\title{
Does volatile sedation with sevoflurane allow spontaneous breathing during prolonged prone positioning in intubated ARDS patients? A retrospective observational feasibility trial
}

\author{
Jascha Heider, Joachim Bansbach, Kai Kaufmann, Sebastian Heinrich, Torsten Loop and Johannes Kalbhenn * (1)
}

\begin{abstract}
Background: Lung-protective ventilation and prolonged prone positioning (PP) are presented as essential in treating acute respiratory distress syndrome (ARDS). The optimal respirator mode, however, remains controversial. Pressuresupported spontaneous breathing (PS) during ARDS provides several advantages, but is difficult to achieve during PP because of respiratory depression as a side effect of sedative drugs. This study was designed to evaluate the feasibility and safety of PS during PP in ARDS patients sedated with inhaled sevoflurane.

Results: Overall, we have observed $4339 \mathrm{~h}$ of prone positioning in 62 patients who had a median of four prone episodes during treatment. Within $3948 \mathrm{~h}$ (91\%), patients were successfully brought into a pressure-supported spontaneous breathing mode. The median duration of each prone episode was $17 \mathrm{~h}$ (IQR 3). Median duration of pressure-supported spontaneous breathing per episode was $16 \mathrm{~h}$ (IQR 5). Just one self-extubation occurred during 276 episodes of PP.

Conclusions and implications: Pressure-supported spontaneous breathing during prolonged prone positioning in intubated ARDS patients with or without ECMO can be achieved during volatile sedation with sevoflurane. This finding may provide a basis upon which to question the latest dogma in ARDS treatment. Our concept must be further investigated and compared to controlled ventilation with regard to driving pressure, lung-protective parameters, muscle weakness and mortality before it can be routinely applied.
\end{abstract}

Keywords: ECMO, ARDS, Prone positioning, Sedation, Spontaneous breathing, Sevoflurane, Volatile anesthesia

\section{Background}

Adherence to a bundle of respirator settings termed "lung-protective ventilation" $[1,2]$ and prolonged prone positioning (PP) [3-5] are presented as essential in guidelines for treating patients with acute respiratory distress syndrome (ARDS) [6]. What the optimal respirator mode in ARDS is, however, remains controversial [7]: pressure-supported spontaneous breathing (PS) lowers intrathoracic and driving pressure, improves

\footnotetext{
*Correspondence: Johannes.kalbhenn@uniklinik-freiburg.de Department of Anesthesiology and Critical Care, Medical Center University of Freiburg, Faculty of Medicine, University of Freiburg, Hugstetter Strasse 55, 79106 Freiburg, Germany
}

oxygenation, may partly recruit atelectatic areas of the lung $[8,9]$, supports the diaphragm preventing lung collapse [10], does not worsen right ventricular function $[11,12]$ and prevents patients from ICU-acquired muscle weakness [13-17]. The risk of spatial hyperinflation due to increased transpulmonary pressure, ventilator-topatient-dys-synchrony and the risk of ventilator induced lung injury (VILI) as a consequence $[18,19]$ on the other hand may support controlled ventilation and even muscle relaxation in early ARDS to achieve "lung protection" [20]. In a large international observational trial, spontaneous breathing was present in $46 \%$ of patients with severe ARDS but had no effect on mortality. Spontaneous 
breathing was associated with more ventilator-free days and a briefer ICU stay [21].

In recent trials, patients were mechanically ventilated in a controlled ventilatory mode during PP under deep intravenous sedation $[3,4,22]$. The combination of PP and supported spontaneous breathing has not been systemically evaluated so far due to the dilemma between sedation necessary to tolerate PP and sedative-induced depression of respiratory genesis $[15,23,24]$. Sedatives compromise respiratory genesis in a dose-related manner. In contrast to intravenous sedatives; however, an effective sevoflurane concentration is traceable in real time in the exhaled air. Moderate sedation is thus more likely achievable concomitant with spontaneous breathing [25]. It also enhances a faster recovery and shortens time to extubation in ICU patients [26]. Inhaled sevoflurane is known to be safe when applied for a prolonged period during intensive care unit (ICU) therapy [27].

We hypothesized that pressure-supported spontaneous breathing during PP would be feasible during volatile sedation with sevoflurane. In this retrospective observational trial, we evaluated a cohort of patients with moderate or severe ARDS. The primary endpoint was length of PS in hours related to the PP duration. Secondary outcome parameter was the incidence of sedation-related unexpected events.

\section{Methods}

Patients were recruited in a German University ARDS center und ECMO center endowed according to international recommendations [28] and certified by the German Society of Anesthesiology and Intensive Care Medicine (DGAI). Patients with ARDS according to the Berlin definition [29] (onset within 1 week; bilateral opacities, not explained by cardiac failure or hypervolemia; $\mathrm{paO} 2 / \mathrm{FiO} 2<300$ with $\mathrm{PEEP} \geq 5 \mathrm{cmH}_{2} \mathrm{O}$ ) were treated according to a standardized departmental protocol (Fig. 1). When computed tomographic findings failed to support ARDS, the diagnosis was rejected. Patient data are anonymously collected in a local ARDS registry. The study was approved by the local ethics committee (EK 141/17) and the general contract governing medical treatment. It was confirmed that no further informed consent was necessary because of the study's descriptive, non-interventional and anonymous design which was planned and designed in accordance with the initiative for Strengthening the Reporting of Observational Studies in Epidemiology (STROBE), using the suggested checklist for epidemiological cohort studies [30].

\section{Patients}

The local ARDS registry was scanned for all patients treated for at least $24 \mathrm{~h}$ with a prescription of sevoflurane since the registry's introduction in 2014. Patients not at least 18 years old were excluded. Patients not suitable for PP (e.g., external pelvic fixateur, spine injury, abdomen apertum, etc.) or those who only revealed side positioning or incomplete PP $\left(130^{\circ}\right)$ were also excluded from analysis.

\section{Analgosedation}

Sedation was established via inhaled sevoflurane (Sevoflurane Baxter, Baxter Germany GmbH, Unterschleissheim, Germany) applied continuously with the AnaConDa $^{\mathrm{TM}}$ System (Sedana Medical AB, Danderyd, Sweden). Target xMAC (minimal alveolar concentration) was $0.4-0.6$, resulting in an endtidal concentration between 0.5 and $1.3 \mathrm{Vol} \%$ depending on sex and age. Exhaled sevoflurane was measured with a "Vamos" monitor system (Drägerwerk AG \& Co. KG, Lübeck, Germany). Volatiles are not yet licensed to sedate ICU patients; therefore, this indication is off-label use. When connecting an AnaConDa ${ }^{\mathrm{TM}}$ to Dräger Evita ${ }^{\circledR}$ Infinity $^{\circledR}$ V500 respirator, it is mandatory to continuously measure the inspiratory and expiratory sevoflurane concentration. With this setting, inhalative sedation has proven to be safe for ICU sedation and is covered by national guidelines [31].

Sedation target during PP was a calm patient without pronounced or potentially harmful body movement concordant with preserved sufficient spontaneous breathing $(\mathrm{pH}>7.2)$. Limited by the difficulty to accurately assess the Richmond Agitation and Sedation Scale (RASS) [32] in PP, this most likely corresponds to a RASS score of -4 ("no response to voice, but movement or eye opening to physical stimulation"). When returning to supine positioning, sevoflurane was immediately discontinued aiming for a RASS Score of 0 for early mobilization and physiotherapy.

Patients also received basic analgesia with opioids, mainly gastric-retarded morphine or oxycodone. Especially during the start of the study period, patients received continuously infused sufentanil instead. Intravenous piritramid, a low-potent opioid, was additionally applied as nurse-controlled analgesia (NCA). As the visual analogue scale (VAS) cannot be applied in pronely positioned sedated patients, criteria for opioid application were symptoms of stress or pain like tachypnea, tachycardia, sweating, body motion, etc.

\section{Ventilator settings during prone positioning}

Positive end expiratory pressure was set at between 12 and 16 mbar. Inspiratory fraction of oxygen $\left(\mathrm{FiO}_{2}\right)$ was set aiming for an arterial oxygen partial pressure $\left(\mathrm{paO}_{2}\right)$ of $\geq 60 \mathrm{mmHg}$. Patients were converted to the pressure-supported spontaneous breathing (PS) 


\begin{tabular}{|c|c|c|c|}
\hline \multicolumn{4}{|c|}{ Admission / identification of a patient suspicious for ARDS $\left(\mathrm{paO}_{2} / \mathrm{FiO}_{2}<300 \mathrm{mmHg}\right)$} \\
\hline \multicolumn{3}{|l|}{ Diagnostic workup } & \\
\hline \multicolumn{3}{|c|}{$\begin{array}{l}\text { - BiPAP ventilation, PEEP } 14-18 \mathrm{mbar} \\
\text { - Blood gas analysis + Laboratory blood test + provisioning of blood products } \\
\text { - Bronchoscopy } \\
\rightarrow \text { Mandatory microbiological and virological diagnostics } \\
\rightarrow \text { Consider fiberoptic endotracheal intubation if patient is not intubated } \\
\text { - Change of catheters, establish nas ogastricfeeding tube } \\
\rightarrow \text { Obtain blood cultures } \\
\text { - Initiate antimicrobial therapy if indicated } \\
\text { - RV- Echocardiography } \\
\text { - Whole body CT scan }\end{array}$} & $\frac{N}{J}$ \\
\hline 23 & \multirow{3}{*}{$\overbrace{\text { YES }}^{\text {NO }}$} & & \\
\hline $\begin{array}{l}\text { Confirmed moderate/severe ARDS? } \\
\left(\mathrm{paO}_{2} / \mathrm{FiO}_{2}<200 \mathrm{mmHg}\right)\end{array}$ & & \multicolumn{2}{|l|}{$\begin{array}{l}\text { Specific treatment } \\
\text { according to diagnose }\end{array}$} \\
\hline 亿 YES & & & \\
\hline Contraindications for prone positioning? & & $\begin{array}{l}\text { Seek consultant's help and } \\
\text { consider alternatives }\end{array}$ & \\
\hline
\end{tabular}

Preparation for prone positioning (max. 2 hours after admission)

- Head cup

- Alternating pressure air mattress

- Anaconda-S®, Sevoflurane

- Anesthetic measurement system with monitor

- Scavening system/Gas exhaustion<smiles>C1=CC2CC12</smiles>

Prone positioning
- Sevoflurane $0.4-0.6 \times$ MAC via Anaconda®
- Cushen pressure-exposed body surface
Improvement of gas exchange?
YES

\begin{tabular}{|c|c|}
\hline Continue prone positioning & \\
\hline 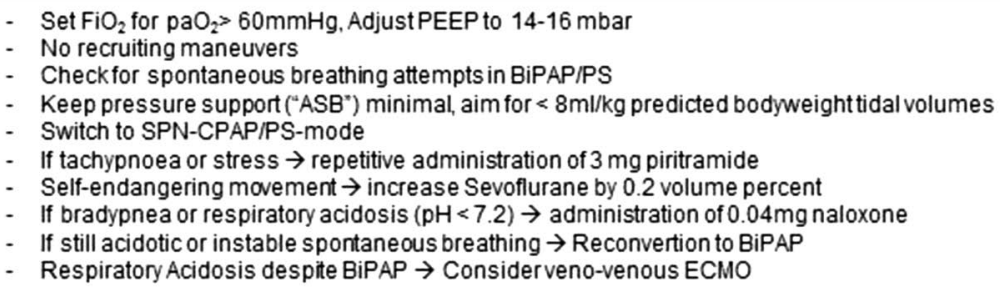 & $\begin{array}{l}\vec{f} \\
\vec{\sigma} \\
\vec{D} \\
\bar{c} \\
\frac{5}{n}\end{array}$ \\
\hline 5 & \\
\hline Supine positioning & \multirow{2}{*}{$\underset{\substack{0 \\
\hdashline}}{\stackrel{0}{0}}$} \\
\hline $\begin{array}{l}\text { - Stop Sevoflurane, Remove Anaconda-S@ } \\
\text { - Bring patient in sitting position, mobilize if not contraindicated } \\
\text { - Perform active physiotherapy, bed pedal exerciser, check CamICU, VAS }\end{array}$ & \\
\hline
\end{tabular}

Fig. 1 Departmental standard operating procedure for workup in ARDS 
mode "SPN-CPAP/PS" (spontaneous-continuous positive airway pressure/pressure support) at the Evita ${ }^{\circledR}$ Infinity ${ }^{\circledR}$ V500 respirator (Drägerwerk AG \& Co. KG, Lübeck, Germany). Criteria for reconverting to PCV were respiratory acidosis with blood $\mathrm{pH}<7.2$. Respirator settings were switched to the pressure-controlled ventilation (PCV) mode "PC-BIPAP" (pressure control biphasic positive airway pressure); opioid application was reduced and when patients started breathing spontaneously, the respirator again was switched to SPNCPAP/PS mode. If spontaneous breathing could not be established promptly and accumulated opioids were the most likely reason, naloxone was administered in $0.04 \mathrm{mg}$ steps in line with the responsible nurse's discretion. Basic opioid therapy was then reduced. Nurses were advised to aim for tidal volumes of $\leq 8 \mathrm{ml} / \mathrm{kg}$ predicted body weight [2] (males $=50+0.91$ [height $(\mathrm{cm})-152.4$ ] $\mathrm{kg}$; females $=45.5+0.91[$ height $(\mathrm{cm})-152.4] \mathrm{kg})$ by modifying pressure support and endtidal sevoflurane concentration and applying opioids. The detailed standard operating procedure is illustrated in Fig. 1.

\section{Extracorporeal membrane oxygenation (ECMO)}

High flow venovenous ECMO was indicated and implanted by two experienced intensivists when $\mathrm{paO}_{2} /$ $\mathrm{FiO}_{2}$ fell below 60 despite PP or when respiratory acidosis was not controllable with lung-protective ventilator settings. Contraindications were lung failure not likely to resolve within a foreseeable period, prolonged ventilator dependence before referral, malignancies and severe underlying diseases. Details about ECMO assembly and thresholds have been published elsewhere [33, 34].

\section{Data collection}

Detailed data about the ventilation mode, circulatory parameters, RASS and sevoflurane consumption were collected from the electronic chart (Copra 5, Copra Systems GmbH, Berlin, Germany). Reports on the patients' condition were documented every 8th hour by both nurses and intensivists in the electronic chart. Every shift report was screened with special regard to unexpected events, especially harmful body motion, self-extubation or hemodynamic instability for this analysis.

\section{Statistics}

Data were collected in Microsoft Excel sheets (Microsoft, Redmond, Washington, USA). Statistical analysis was performed with GraphPad InStat ${ }^{\circledR}$ (GraphPad Software Inc, La Jolla, California, USA) to calculate the median and inter quartile range (IQR).

\section{Results}

Patients

For details on patient selection, please see Fig. 2.

Cohort characteristics are listed in Table 1.

Three patients in PP already presented RASS values of -5 ; thus, prescribed sevoflurane was not applied in line with the responsible nurse's discretion. Two patients with only "mild" ARDS had been intubated before for other reasons and were brought to PP because respiratory function would probably worsen in due course.

\section{Primary endpoint: duration of pressure-supported spontaneous breathing}

Overall, $4339 \mathrm{~h}$ of prone positioning have been observed. Within 3948 h (91\%), patients were switched successfully to a pressure-supported spontaneous breathing mode (Fig. 3).

The median duration of each prone episode was $17 \mathrm{~h}$ (IQR 3). Median duration of pressure-supported spontaneous breathing per episode was $16 \mathrm{~h}$ (IQR 5). Results are listed in Table 2.

\section{Reasons for failed conversion to pressure-supported spontaneous breathing}

As presented in Fig. 1, conversion to PS was intended when safe preconditions had been established. If $\mathrm{pH}$ was $<7.2$, patients were reconverted to PCV. We identified 2 factors for failed PS attempts: Some patients suffered from accumulation of opioids or sedatives they had received in the referring hospitals before. Despite treatment with naloxone, PS could not be established promptly. The other cohort failed breathing spontaneously were ECMO patients with very low tidal volumes (<100-150 ml). In these patients, alveolar concentration of sevoflurane was difficult to set and obviously too low to satisfactorily suppress agitation.

\section{Complications and unexpected events}

Unexpected events related to prone positioning or inhaled sedation are listed in Table 3.

Three circulatory arrests have been observed in temporary but not clearly in causal connection with prone positioning and sevoflurane-sedation:

One patient (number 051) suffered from septic shock with abdominal focus. Because of multiorgan failure und underlying morbidities, this patient had been considered ECMO-unsuitable. He was turned to prone positioning as ultima ratio because of severe hypoxia. Despite mildly improved oxygenation, he died of uncontrolled lactic acidosis.

One patient (number 097) connected to venovenous ECMO developed severe septic shock and acute renal 


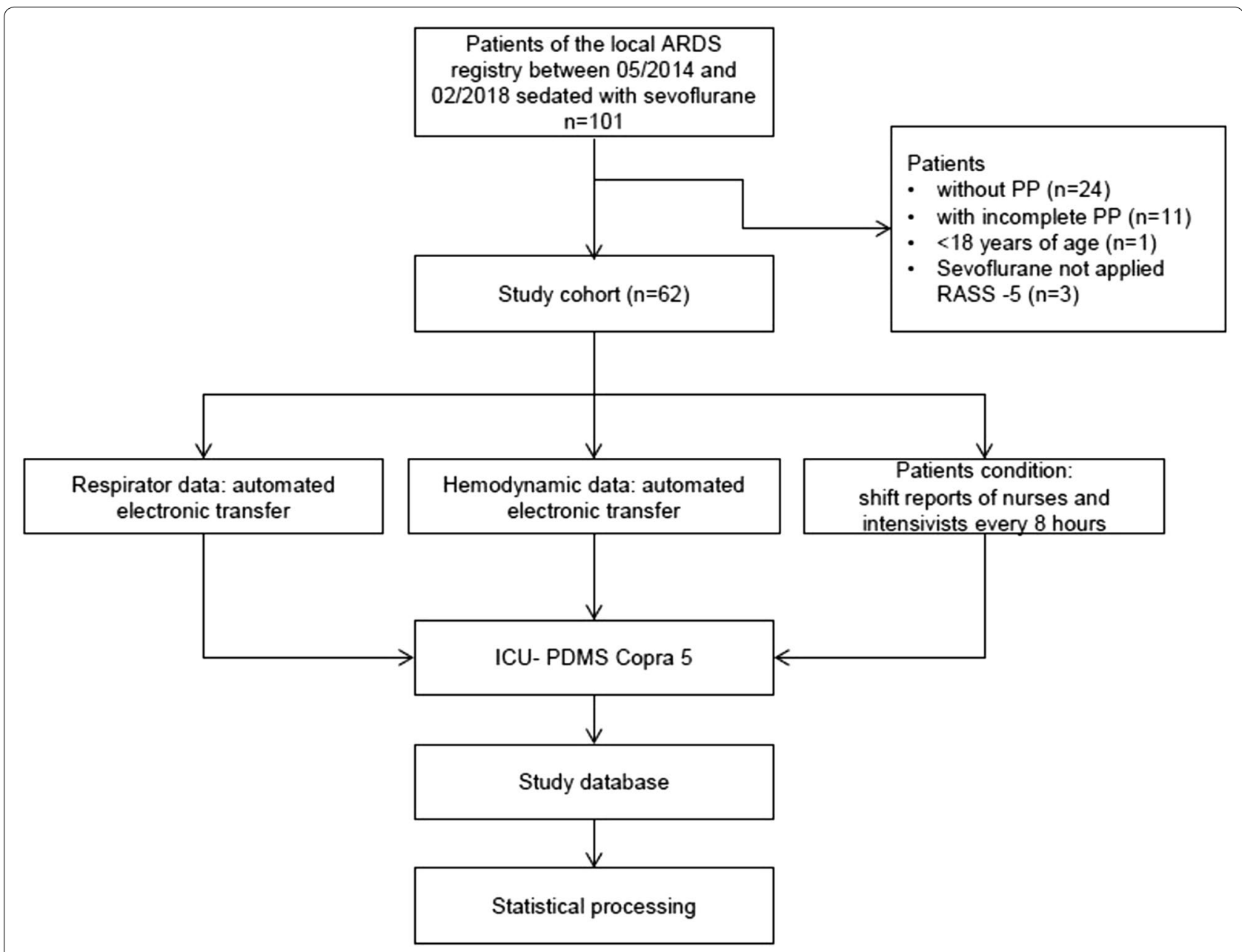

Fig. 2 Selection of patients and data generation

failure following pneumonia. Due to metabolic acidosis and increased serum potassium, he presented with ventricular tachycardia and severe hypotension and was successfully resuscitated after turning to supine position but died from septic shock in the following hours.

One patient (number 101) developed right heart failure. He was turned back and resuscitation was started. After returning to spontaneous circulation continuously infused epinephrine and inhaled nitric oxide were started. Unfortunately, the patient died the next day.

\section{Discussion}

This observational feasibility trial is the first to systemically evaluate inhaled sedation with sevoflurane for PP in combination with PS. Conversion to PS succeeded in 91\% of the cumulative hours of PP. During 276 episodes with over $4000 \mathrm{~h}$ of PP, no related fatal event occurred. With a median RASS value of -4.5 , a sufficient sedation depth was achieved in 59 (95\%) out of 62 patients with a combination of sevoflurane and opioids.

The finding that PS during PP in intubated ARDS patients is safely achievable during volatile sedation with sevoflurane forms the basis from which to question the current dogma in ARDS treatment. On the other hand, this approach inherits the risk of hyperinflation due to increased respiratory effort. This concept must therefore be investigated in comparison with controlled ventilation in terms of driving pressure, lung-protective parameters, muscle weakness and mortality before it can be routinely applied.

\section{Tolerating Prone Positioning and ventilation} versus avoidance of long lasting sedatives

There is still no convincing evidence for what constitutes the optimal respirator mode to achieve lung-protective parameters and to decrease driving pressure in ARDS [17]. In the 2010 "PROSEVA" - Trial authors compared 
Table 1 Patient characteristics $(n=62)$

\begin{tabular}{ll}
\hline Patient characteristics & \\
\hline Sex, $n$ (\%) & $45(73)$ \\
Male & $17(27)$ \\
Female & $56(25.75)$ \\
Age [years], median (IQR) & $25.4(4.8)$ \\
Body mass index [m// ${ }^{2}$, median (IQR) & \\
Reason of ARDS, $n$ (\%) & $16(26)$ \\
Bacterial lung infection & $15(24)$ \\
Aspirationpneumonitis/aspirationpneumonia & $13(21)$ \\
Influenza & $7(11)$ \\
ARDS secondary to extrapulmonary infection & $3(5)$ \\
Polytrauma & $8(13)$ \\
Others (post-lung surgery/transplant, etc.) & 47 \\
ICU Mortality [\%] & $15(14)$ \\
ICU stay [days], median, (IQR) & \\
PaO $/$ /FiO ${ }_{2}$ at ICU admission/before ECMO implantation by & \\
ECMO outreach team, $n$ (\%) & $2(3)$ \\
$201-300$ & $26(42)$ \\
$101-200$ & $34(55)$ \\
$\leq 100$ & $20(12)$ \\
TISS-10, median, (IQR) & $48(17.25)$ \\
SAPS II, median, (IQR) & \\
\hline
\end{tabular}

TISS Therapeutic Intervention Scoring System [35], SAPS Simplified Acute Physiology Score [36]

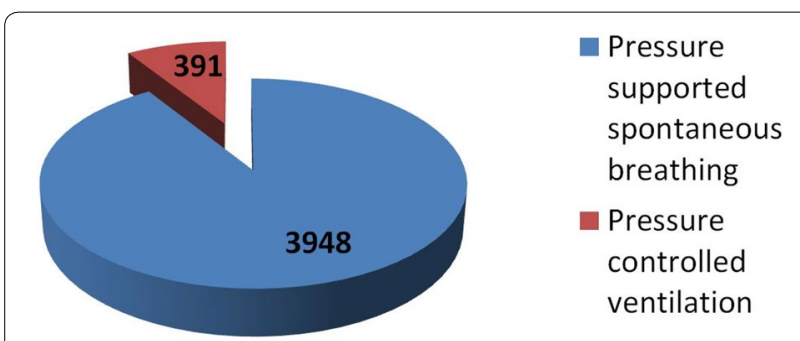

Fig. 3 Respirator mode during prone positioning (cumulative hours)

controlled ventilation and controlled ventilation in addition with muscle relaxation in ARDS. Patients revealed significantly better survival when they additionally received the muscle relaxant cis-atracurium in early ARDS [38]. Anti-inflammatory effects via improved patient-ventilator synchrony have been discussed in conjunction with this finding. Deep sedation is recommended when muscle relaxants are used. Patients in the "PROSEVA" Trial in both groups were deeply sedated to a Ramsey Score of 6 ("patient exhibits no response"). In contrast to this approach, intensivists have become aware that deep sedation and ICU-acquired muscle weakness lower survival and quality of life after hospitalization $[39,40]$. A relevant side effect of prolonged sedation is a loss of muscle strength [23]. Current guidelines therefore ask for conscious patients who can interact and actively participate during their healing process [15, 31, 41, 42]. Inhaled sevoflurane [43] allows a compromise: Sufficient sedation during PP and rapid awakening [44] help enable active physiotherapy and mobilization during episodes of supine positioning.

Crotti et al. [45] found that spontaneous breathing in ARDS during ECMO was feasible in only $30 \%$ of her patients. All of them received intravenous sedative drugs. Pressure-supported spontaneous breathing was achieved in $95 \%$ of our patients for more than $90 \%$ of the cumulative time in prone positioning. In our opinion, this is an effect of the beneficial properties of sevoflurane: Mild and moderate concentrations below depressive effects to the respiratory genesis can easily be set compared to intravenous sedatives.

\section{Advantages of spontaneous breathing}

There are various possible advantages of PS during ARDS: Muscle activation may help prevent diaphragm atrophy [14] and active inspiration may help distribute air within the lung more evenly $[46,47]$ and in areas with low ventilation/perfusion ratios. Spontaneous breathing has the potential to lower intrathoracic pressure and therefore contribute preventing right heart failure-a highly relevant comorbidity contributing to ARDS mortality. In addition to hypoxic pulmonary arterial vasoconstriction, increased intrathoracic pressure inherits the risk of impairing right ventricular function by hindering venous blood's return to the right atrium and increasing right ventricular afterload [12, 16, 48].

The main concern associated with spontaneous breathing during ARDS is the increase in transpulmonary pressure with consecutive spatial hyperinflation. This effect seems to mainly threaten the ventral areas of the lung during supine position. Stabilizing the chest wall's anterior through the patient's bodyweight in PP alleviates this theoretical harm during PS $[5,18,49]$.

\section{Respiratory drive and respiratory genesis}

The genesis of respiration and the respiratory drive are controlled by complex feedback loops and dependent on various parameters $\left(\mathrm{paO}_{2}, \mathrm{paCO}_{2}, \mathrm{pH}\right.$, inflammation, body temperature, agitation, etc.) described elsewhere [50, 51]. Target values for paO2 [52] and blood $\mathrm{pH}[53,54]$ have been discussed especially. While better oxygenation obviously reduces inspiratory effort and the respiratory rate, it is difficult to achieve in severe ARDS. It is even more difficult to define an evidence-based threshold for blood $\mathrm{pH}$ before converting patients to PS. Crotti for example included 30 patients with ARDS in her spontaneous breathing study [45]. 
Table 2 Details on episodes of prone positioning

\begin{tabular}{ll}
\hline Episodes of prone positioning & \\
Overall, $n$ & 276 \\
Per patient, median, (IQR) & $4(4)$ \\
With ECMO & 152 \\
Without ECMO & 124 \\
Sevoflurane consumption/episode [ml], median (IQR) & $48(17)$ \\
Duration [h], median (IQR) & $17(3)$ \\
Cumulative hours of PP & 4339 \\
Cumulative hours of PS during PP & 3948 \\
RASS, median (IQR) during PP & $-4.5(1.5)$ \\
pH before conversion to PS, median (IQR) & \\
Prone episode 1 & $7.313(0.116)$ \\
Prone episode 2 & $7.35(0.102)$ \\
Prone episode 3 & $7.356(0.103)$ \\
Prone episode 4 & $7.374(0.117)$ \\
Prone episode 5 & $7.371(0.092)$ \\
\hline
\end{tabular}

PP Prone positioning, PS pressure-supported spontaneous breathing; RASS Richmond Agitation and Sedation Scale [37]

She did not find a significant difference between blood $\mathrm{pH}$ values in the 22 patients in whom spontaneous breathing was unfeasible and eight patients with spontaneous breathing. In our workup flowchart (Fig. 1), we chose arbitrary thresholds of $>60 \mathrm{mmHg}$ for paO2 and $\mathrm{pH}>7.2$, respectively, to establish $\mathrm{FiO}_{2}$ and pressure support. The analgosedation regimen based mainly on varying the endtidal sevoflurane concentration and opioid application does not specifically address all the aforementioned parameters. During over $90 \%$ of cumulative hours of PS during PP, however, it really worked in clinical practice even in patients with blood $\mathrm{pH}$ values below 7.2.

\section{Effects of inhaled anesthetics}

Many side effects of volatile anesthetics have been reported recently $[26,55-57]$ which may partly be advantageous in ARDS: Sedation with sevoflurane improves oxygenation and decreases levels of inflammatory markers in ARDS compared to midazolam [57]. Bronchodilatory, anti-inflammatory [58] and even anti-bacterial properties $[59,60]$ have been reported. Cardio-protective effects also have been discussed [61].

\section{Additional effects}

Some patients in this study were able to turn to PP themselves with assistance. This advantage is chosen, when patients are alert and calm while in supine position and when physiotherapists confirm sufficient muscle strength. Lines and tubes are secured by the nurse and an intensivist at the head-end of the bed. Patients are instructed beforehand and then allowed to turn around and lay themselves in prone positioning until they feel comfortable. They are able to communicate with their hands and by the help of a mirror reflecting the face. Sevoflurane is not initiated until patients have clearly agreed. We believe that this innovation may help us lower the incidence of skin bruises and positional damage.

\section{Severity of ARDS and mortality}

Mortality was not an endpoint of this study. Most of the patients at ICU admission had severe $(55 \%)$ or moderate (42\%) ARDS. Two intubated patients were admitted to ICU with "mild" ARDS (Table 1). One of them (No 67) was put into PP because pulmonary function was rapidly worsening and severe ARDS developed in due course. The other patient (No 78) was extubated after the first PP episode, and treatment was continued with noninvasive ventilation. Ten patients had been diagnosed with severe

Table 3 Complications and unexpected events related to prone positioning or inhaled sedation

\begin{tabular}{|c|c|c|c|c|}
\hline $\begin{array}{l}\text { Patient } \\
\text { number }\end{array}$ & Type of complication & Reason & Management & Result \\
\hline 063 & $\begin{array}{l}\text { Pharyngeal disloca- } \\
\text { tion of endotracheal } \\
\text { tube }\end{array}$ & $\begin{array}{l}\text { Unclear whether the patient extubated herself } \\
\text { with her tongue or fixation of the tube } \\
\text { unsticked because of salivation }\end{array}$ & $\begin{array}{l}\text { Already spontaneous } \\
\text { breathing } \rightarrow \text { Noninvasive } \\
\text { Ventilation, turned back, re- } \\
\text { intubation }\end{array}$ & $\begin{array}{l}\text { No hypoxia, turned back in PP } \\
\text { after re-intubation }\end{array}$ \\
\hline 019 & Insufficient sedation & Technical defect of Anaconda & Dexmedetomidine infusion & PP continued \\
\hline 094 & Insufficient sedation & Low tidal volume & Sufentanil infusion & PP continued \\
\hline 095 & Insufficient sedation & Low tidal volume & Sufentanil infusion & PP continued \\
\hline 056 & Respiratory acidosis & Unclear & $\begin{array}{l}\text { Controlled ventilation } \rightarrow \text { still } \\
\text { acidodic } \rightarrow \text { turned back to } \\
\text { supine position, Anaconda } \\
\text { removed }\end{array}$ & Still acidotic in supine position \\
\hline 072 & Respiratory acidosis & Retrospectively: kinked tube & Turned back, refixation of tube & PP continued \\
\hline
\end{tabular}


ARDS in primary hospitals and were then connected to ECMO by our outreach team and referred to our ICU. The $47 \%$ mortality in our cohort is therefore comparable or even lower than expected when compared to epidemiological data [62].

\section{Limitations}

This "proof-of-principle" trial's main drawback is its retrospective design. A control group would have been desirable. The use of inhaled anesthetics requires deep understanding of malignant hyperthermia, and dantrolene must be at hand. While absorbers and gas exhaustion systems keep the ambient air load minimal, the global warming potential of sevoflurane is enormous [63]. The Anaconda and the Anaconda-S device increase the dead space by $100 \mathrm{ml}$ and $50 \mathrm{ml}$, respectively, which can increase respiratory acidosis and alveolar concentration of sevoflurane especially in low tidal volumes [64, 65].

\section{Conclusions}

Pressure-supported spontaneous breathing in patients undergoing prone positioning in ARDS is feasible and safe during inhaled sedation with sevoflurane-a concept that challenges current state-of-the-art ARDS therapy. Research should now focus on comparing controlled and pressure-supported spontaneous ventilator settings during PP and the effects on driving pressure, lung-protective parameters, muscle weakness and mortality in a larger cohort. These investigations are essential before the PS approach during PP can be routinely recommended.

\section{Abbreviations \\ ARDS: acute respiratory distress syndrome; BIPAP: biphasic positive airway pressure; CPAP: continuous positive airway pressure; ECMO: extracorporeal membrane oxygenation; ICU: intensive care unit; IQR: interquartile range; PP: (Prolonged) prone positioning; PS: pressure-supported (spontaneous breath- ing); RASS: Richmond Agitation and Sedation Scale; SAPS: Simplified Acute Physiology Score; TISS: Therapeutic Intervention Scoring System.}

\section{Authors' contributions}

JB and JK coordinated the ARDS program at University Freiburg Medical Center and developed the protocol. JH collected the data. TL, KK and SH supported the design of the study. JH, SH and JK performed the statistical analysis. $\mathrm{JH}$ and $\mathrm{JK}$ wrote the manuscript. $\mathrm{TL}, \mathrm{JB}, \mathrm{KK}$ and $\mathrm{SH}$ revised the manuscript. All authors contributed substantially to this work, and all of them revised and have agreed to the final version of the manuscript with full access to all data. All authors read and approved the final manuscript.

\section{Acknowledgements}

The authors wish to thank Thomas Desing for his valuable support in patient data documentation.

\section{Competing interests}

The authors declare that they have no competing interests.

\section{Availability of data and materials}

The datasets consulted during this study are available from the corresponding author on reasonable request.

\section{Consent for publication}

Not applicable.

\section{Ethics approval and consent to participate}

Demographic and specific laboratory details on the patients were anonymously collected prospectively in a local ARDS registry. Protocol-based ARDS therapy is covered by the general contract governing medical treatment. The local ethics committee approved the analysis and publication of these data and confirmed that no specific patient's consent was necessary because of the study's anonymous and observational design (EK 141/17).

\section{Funding}

The article processing charge was funded by the German Research Foundation (DFG) and the Albert Ludwigs University Freiburg through the funding program Open Access Publishing.

\section{Publisher's Note}

Springer Nature remains neutral with regard to jurisdictional claims in published maps and institutional affiliations.

Received: 3 December 2018 Accepted: 18 March 2019

Published online: 25 March 2019

\section{References}

1. Acute Respiratory Distress Syndrome N, Brower RG, Matthay MA, Morris A, Schoenfeld D, Thompson BT, et al. Ventilation with lower tidal volumes as compared with traditional tidal volumes for acute lung injury and the acute respiratory distress syndrome. New Engl J Med. 2000;342(18):1301-8.

2. Fan E, Del Sorbo L, Goligher EC, Hodgson CL, Munshi L, Walkey AJ, et al. An official american thoracic society/european society of intensive care medicine/society of critical care medicine clinical practice guideline: mechanical ventilation in adult patients with acute respiratory distress syndrome. Am J Respir Crit Care Med. 2017;195(9):1253-63.

3. Guerin C, Reignier J, Richard JC, Beuret P, Gacouin A, Boulain T, et al. Prone positioning in severe acute respiratory distress syndrome. New Engl J Med. 2013;368(23):2159-68.

4. Sud S, Friedrich JO, Taccone P, Polli F, Adhikari NK, Latini R, et al. Prone ventilation reduces mortality in patients with acute respiratory failure and severe hypoxemia: systematic review and meta-analysis. Intensive Care Med. 2010;36(4):585-99.

5. Guerin C, Baboi L, Richard JC. Mechanisms of the effects of prone positioning in acute respiratory distress syndrome. Intensive Care Med. 2014;40(11):1634-42.

6. Thompson BT, Chambers RC, Liu KD. Acute respiratory distress syndrome. New Engl J Med. 2017;377(19):1904-5.

7. Mauri T, Cambiaghi B, Spinelli E, Langer T, Grasselli G. Spontaneous breathing: a double-edged sword to handle with care. Ann Transl Med. 2017:5(14):292.

8. Wrigge H, Zinserling J, Neumann P, Defosse J, Magnusson A, Putensen $C$, et al. Spontaneous breathing improves lung aeration in oleic acidinduced lung injury. Anesthesiology. 2003;99(2):376-84.

9. Putensen $\mathrm{C}$, Hering $\mathrm{R}$, Muders T, Wrigge $\mathrm{H}$. Assisted breathing is better in acute respiratory failure. Curr Opin Crit Care. 2005;11(1):63-8.

10. Pellegrini M, Hedenstierna G, Roneus A, Segelsjo M, Larsson A, Perchiazzi $\mathrm{G}$. The diaphragm acts as a brake during expiration to prevent lung collapse. Am J Respir Crit Care Med. 2017;195(12):1608-16.

11. Zochios V, Parhar K, Tunnicliffe W, Roscoe A, Gao F. The right ventricle in ARDS. Chest. 2017;152(1):181-93.

12. Vieillard-Baron A, Matthay M, Teboul JL, Bein T, Schultz M, Magder S, et al. Experts' opinion on management of hemodynamics in ARDS patients: focus on the effects of mechanical ventilation. Intensive Care Med. 2016;42(5):739-49. 
13. Yoshida T, Fujino Y, Amato MB, Kavanagh BP. Fifty Years of Research in ARDS. Spontaneous Breathing during Mechanical Ventilation. Risks, Mechanisms, and Management. Am J Respir Crit Care Med. 2017;195(8):985-92

14. Levine S, Nguyen T, Taylor N, Friscia ME, Budak MT, Rothenberg P, et al. Rapid disuse atrophy of diaphragm fibers in mechanically ventilated humans. New Engl J Med. 2008;358(13):1327-35.

15. Shah FA, Girard TD, Yende S. Limiting sedation for patients with acute respiratory distress syndrome - time to wake up. Curr Opin Crit Care. 2017;23(1):45-51.

16. Grübler MR, Wigger $O$, Berger D, Bloechlinger S. Basic concepts of heart-lung interactions during mechanical ventilation. Swiss Med Wkly. 2017;147:14491

17. Amato MB, Meade MO, Slutsky AS, Brochard L, Costa EL, Schoenfeld $D A$, et al. Driving pressure and survival in the acute respiratory distress syndrome. New Engl J Med. 2015;372(8):747-55.

18. Tonetti T, Cressoni M, Collino F, Maiolo G, Rapetti F, Quintel M, et al. Volutrauma, atelectrauma, and mechanical power. Crit Care Med. 2017;45(3):e327-8.

19. Pelosi P, Rocco PRM, Gama de Abreu M. Close down the lungs and keep them resting to minimize ventilator-induced lung injury. Crit Care. 2018:22(1):72

20. Gattinoni L, Tonetti T, Quintel M. How best to set the ventilator on extracorporeal membrane lung oxygenation. Curr Opin Crit Care 2017;23(1):66-72.

21. van Haren F, Pham T, Brochard L, Bellani G, Laffey J, Dres M, et al. Spontaneous breathing in early acute respiratory distress syndrome: insights from the large observational study to UNderstand the Global Impact of Severe Acute Respiratory FailurE Study. Crit Care Med. 2019;47(2):229-38.

22. Scholten EL, Beitler JR, Prisk GK, Malhotra A. Treatment of ARDS with prone positioning. Chest. 2017;151(1):215-24.

23. Abdelmalik PA, Rakocevic G. Propofol as a risk factor for ICU-acquired weakness in septic patients with acute respiratory failure. Can J Neurol Sci. 2017;44(3):295-303.

24. Munoz-Ortiz J, Munoz-Ortiz E, Lopez-Meraz ML, Beltran-Parrazal L, Morgado-Valle C. Pre-Botzinger complex: generation and modulation of respiratory rhythm. Neurologia. 2016. https://doi.org/10.1016/j.nrlen g.2018.05.006.

25. Delgado-Herrera L, Ostroff RD, Rogers SA. Sevoflurance: approaching the ideal inhalational anesthetic. a pharmacologic, pharmacoeconomic, and clinical review. CNS Drug Rev. 2001;7(1):48-120.

26. Kim HY, Lee JE, Kim HY, Kim J. Volatile sedation in the intensive care unit: a systematic review and meta-analysis. Medicine. 2017;96(49):e8976.

27. Perbet S, Bourdeaux D, Sautou V, Pereira B, Chabanne R, Constantin JM, et al. A pharmacokinetic study of 48-hour sevoflurane inhalation using a disposable delivery system (AnaConDa(R)) in ICU patients. Minerva Anestesiol. 2014;80(6):655-65.

28. Combes A, Brodie D, Bartlett R, Brochard L, Brower R, Conrad S, et al. Position paper for the organization of extracorporeal membrane oxygenation programs for acute respiratory failure in adult patients. Am J Respir Crit Care Med. 2014;190(5):488-96

29. Force ADT, Ranieri VM, Rubenfeld GD, Thompson BT, Ferguson ND, Caldwell $\mathrm{E}$, et al. Acute respiratory distress syndrome: the Berlin definition. JAMA. 2012;307(23):2526-33.

30. Vandenbroucke JP, von Elm E, Altman DG, Gotzsche PC, Mulrow CD, Pocock SJ, et al. Strengthening the reporting of observational studies in epidemiology (STROBE): explanation and elaboration. International journal of surgery. 2014;12(12):1500-24.

31. Taskforce DAS, Baron R, Binder A, Biniek R, Braune S, Buerkle H, et al. Evidence and consensus based guideline for the management of delirium analgesia, and sedation in intensive care medicine. Revision 2015 (DASGuideline 2015)—short version. German Med Sci GMS e-J. 2015;13.

32. Ely EW, Truman B, Shintani A, Thomason JW, Wheeler AP, Gordon S, et al. Monitoring sedation status over time in ICU patients: reliability and validity of the Richmond Agitation-Sedation Scale (RASS). JAMA. 2003;289(22):2983-91.

33. Krueger K, Schmutz A, Zieger B, Kalbhenn J. Venovenous extracorporeal membrane oxygenation with prophylactic subcutaneous anticoagulation only: an observational study in more than 60 patients. Artif Organs. 2017:41(2):186-92.
34. Kalbhenn J, Schlagenhauf A, Rosenfelder S, Schmutz A, Zieger B. Acquired von Willebrand syndrome and impaired platelet function during venovenous extracorporeal membrane oxygenation: rapid onset and fast recovery. J Heart Lung Transplant Off Publ Int Soc Heart Transplant. 2018;37(8):985-91.

35. Keene AR, Cullen DJ. Therapeutic Intervention Scoring System: update 1983. Crit Care Med. 1983:11(1):1-3.

36. Le Gall JR, Lemeshow S, Saulnier F. A new Simplified Acute Physiology Score (SAPS II) based on a European/North American multicenter study. JAMA. 1993;270(24):2957-63.

37. Sessler CN, Gosnell MS, Grap MJ, Brophy GM, O'Neal PV, Keane KA, et al. The Richmond Agitation-Sedation Scale: validity and reliability in adult intensive care unit patients. Am J Respir Crit Care Med. 2002;166(10):1338-44.

38. DAS-Taskforce, Baron R, Binder A, et al. Evidence and consensus based guideline for the management of delirium, analgesia, and sedation in intensive care medicine. Revision 2015 (DAS-Guideline 2015) Ger Med Sci. 2015;13:Doc19. https://doi.org/10.3205/000223

39. Hermans $G$, Van den Berghe $G$. Clinical review: intensive care unit acquired weakness. Crit Care. 2015;19:274

40. Balzer F, Weiss B, Kumpf O, Treskatsch S, Spies C, Wernecke KD, et al. Early deep sedation is associated with decreased in-hospital and two-year follow-up survival. Crit Care. 2015;19:197.

41. Patel SB, Kress JP. Sedation and analgesia in the mechanically ventilated patient. Am J Respir Crit Care Med. 2012;185(5):486-97.

42. Devlin JW, Skrobik Y, Gelinas C, Needham DM, Slooter AJC, Pandharipande PP, et al. Clinical Practice Guidelines for the Prevention and Management of Pain, Agitation/Sedation, Delirium, Immobility, and Sleep Disruption in Adult Patients in the ICU. Crit Care Med. 2018;46(9):e825-73.

43. Patel SS, Goa KL. Sevoflurane. A review of its pharmacodynamic and pharmacokinetic properties and its clinical use in general anaesthesia. Drugs. 1996;51(4):658-700.

44. Mesnil M, Capdevila $X$, Bringuier $S$, Trine PO, Falquet $Y$, Charbit J, et al. Long-term sedation in intensive care unit: a randomized comparison between inhaled sevoflurane and intravenous propofol or midazolam. Intensive Care Med. 2011;37(6):933-41.

45. Crotti S, Bottino N, Ruggeri GM, Spinelli E, Tubiolo D, Lissoni A, et al. Spontaneous breathing during extracorporeal membrane oxygenation in acute respiratory failure. Anesthesiology. 2017;126(4):678-87.

46. Blankman P, Hasan D, van Mourik MS, Gommers D. Ventilation distribution measured with EIT at varying levels of pressure support and neurally adjusted ventilatory assist in patients with ALI. Intensive Care Med. 2013;39(6):1057-62

47. Putensen C, Mutz NJ, Putensen-Himmer G, Zinserling J. Spontaneous breathing during ventilatory support improves ventilation-perfusion distributions in patients with acute respiratory distress syndrome. Am J Respir Crit Care Med. 1999:159(4 Pt 1):1241-8.

48. McLean B. Hemodynamics of acute right heart failure in mechanically ventilated patients with acute respiratory distress syndrome. Crit Care Nurs Clin North Am. 2015;27(4):449-67.

49. Tonetti T, Vasques F, Rapetti F, Maiolo G, Collino F, Romitti F, et al. Driving pressure and mechanical power: new targets for VILI prevention. Ann Transl Med. 2017:5(14):286.

50. Petitjeans F, Pichot C, Ghignone M, Quintin L. Early severe acute respiratory distress syndrome: What's going on? Part II: controlled vs. spontaneous ventilation? Anaesthesiol Intensive Ther. 2016;48(5):339-51.

51. Petitjeans F, Pichot C, Ghignone M, Quintin L. Building on the Shoulders of Giants: Is the use of Early Spontaneous Ventilation in the Setting of Severe Diffuse Acute Respiratory Distress Syndrome Actually Heretical? Turk J Anaesthesiol Reanim. 2018:46(5):339-47.

52. Pesenti A, Rossi N, Calori A, Foti G, Rossi GP. Effects of short-term oxygenation changes on acute lung injury patients undergoing pressure support ventilation. Chest. 1993;103(4):1185-9.

53. Crotti S, Bottino N, Spinelli E. Spontaneous breathing during veno-venous extracorporeal membrane oxygenation. J Thorac Dis. 2018;10(Suppl 5):S661-9.

54. Hickling KG, Henderson SJ, Jackson R. Low mortality associated with low volume pressure limited ventilation with permissive hypercapnia in severe adult respiratory distress syndrome. Intensive Care Med. 1990;16(6):372-7. 
55. Farhan H, Grabitz SD, Ruscic KJ, Eikermann M. Proper selection of sedative drugs improves outcomes: volatile anesthetics are surgeons' best friends. Ann Transl Med. 2017:5(5):122.

56. Brioni JD, Varughese $S$, Ahmed R, Bein B. A clinical review of inhalation anesthesia with sevoflurane: from early research to emerging topics. J Anesthesia. 2017;31(5):764-78.

57. Jabaudon M, Boucher P, Imhoff E, Chabanne R, Faure JS, Roszyk L, et al. Sevoflurane for Sedation in Acute Respiratory Distress Syndrome. A Randomized Controlled Pilot Study. Am J Respir Crit Care Med. 2017;195(6):792-800.

58. Schilling T, Kozian A, Senturk M, Huth C, Reinhold A, Hedenstierna G, et al. Effects of volatile and intravenous anesthesia on the alveolar and systemic inflammatory response in thoracic surgical patients. Anesthesiology. 2011;115(1):65-74.

59. Martinez-Serrano M, Geronimo-Pardo M, Martinez-Monsalve A, CrespoSanchez MD. Antibacterial effect of sevoflurane and isoflurane. Revista espanola de quimioterapia: publicacion oficial de la Sociedad Espanola de Quimioterapia. 2017;30(2):84-9.

60. Imbernon-Moya A, Ortiz-de Frutos FJ, Sanjuan-Alvarez M, PorteroSanchez I, Merinero-Palomares R, Alcazar V. Topical sevoflurane for chronic venous ulcers infected by multi-drug-resistant organisms. Int Wound J. 2017;14(6):1388-90.

61. Lemoine S, Tritapepe L, Hanouz JL, Puddu PE. The mechanisms of cardioprotective effects of desflurane and sevoflurane at the time of reperfusion: anaesthetic post-conditioning potentially translatable to humans? Br J Anaesth. 2016;116(4):456-75.

62. Bellani G, Laffey JG, Pham T, Fan E, Brochard L, Esteban A, et al. Epidemiology, patterns of care, and mortality for patients with acute respiratory distress syndrome in intensive care units in 50 countries. JAMA 2016;315(8):788-800.

63. Ryan SM, Nielsen CJ. Global warming potential of inhaled anesthetics: application to clinical use. Anesth Analg. 2010;111(1):92-8.

64. Farrell R, Oomen G, Carey P. A technical review of the history, development and performance of the anaesthetic conserving device "AnaConDa" for delivering volatile anaesthetic in intensive and post-operative critical care. J Clin Monit Comput. 2018;32(4):595-604.

65. de la Matta-Martin M, Lopez-Herrera D, Luis-Navarro JC, Lopez-Romero $J$ L. Effects of inhalational anaesthesia with low tidal volume ventilation on end-tidal sevoflurane and carbon dioxide concentrations: prospective randomized study. Rev Esp Anestesiol Reanim. 2014;61(2):78-86.

\section{Submit your manuscript to a SpringerOpen ${ }^{\odot}$ journal and benefit from:}

- Convenient online submission

- Rigorous peer review

- Open access: articles freely available online

- High visibility within the field

- Retaining the copyright to your article

Submit your next manuscript at $\gg$ springeropen.com 